\title{
Magnetic anchor-guided endoscopic submucosal dissection using a stainless steel anchor
}

Colorectal endoscopic submucosal dissection (ESD) is technically difficult and involves long procedure times with the risk of perforation because of the thinness of the muscularis propria and the poor maneuverability of the endoscope $[1,2]$. Magnetic anchor-guided (MAG) systems using neodymium magnets have been reported to be useful in resolving the difficulties of ESD [3,4]. However, a remaining problem with this procedure has been the inability to deliver the magnetic anchor through the scope [5].

A 69-year-old woman was referred to our hospital for a laterally spreading tumor in the ascending colon ( $\mathbf{F i g . 1}$ ). As the first step, after injection of saline into

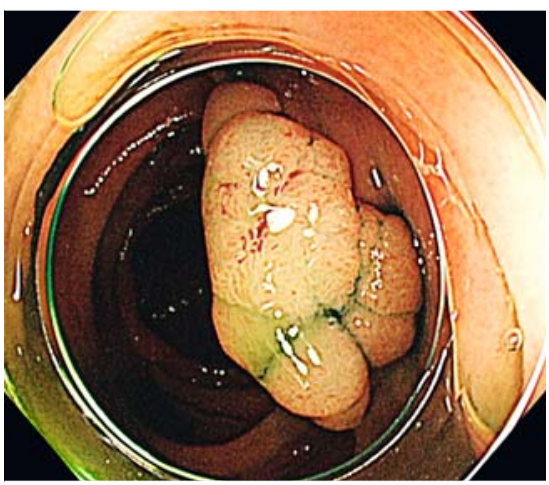

Fig. 1 Endoscopic image of the lesion in the ascending colon. the submucosa, a circumferential mucosal incision was made using the Endosaber (Sumitomo Bakelite, Tokyo, Japan) ( $>$ Fig.2). Next, a stainless steel anchor connected to an endoclip (Zeoclip; Zeon Medical Inc., Tokyo, Japan) (\$Fig.3a) was attached to the proximal mucosal edge of the lesion without retrieving and reinserting the endoscope as would be required in conventional MAG-ESD. The external neodymium magnet was locked on to a flexible arm (FA-M-VC2; SFC Co. Ltd., Kanagawa, Japan) that allowed it to be held in position during ESD, supported by an assistant ( $\triangleright$ Fig. $\mathbf{3} \mathbf{b}$ ). The desired countertraction with good visualization was obtained using this external magnet,

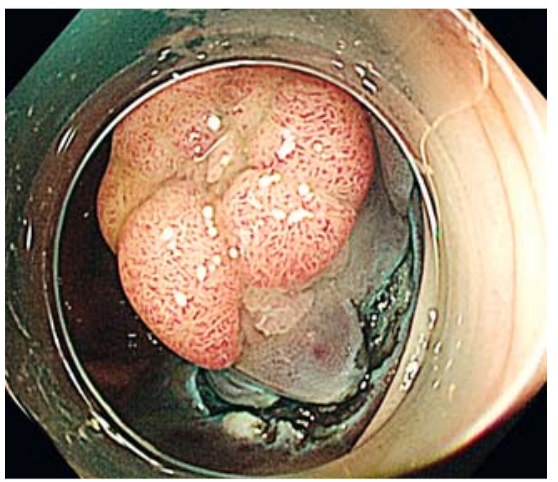

Fig. 2 After partial dissection: mucosal edge of the lesion before attachment of the stainless steel anchor.

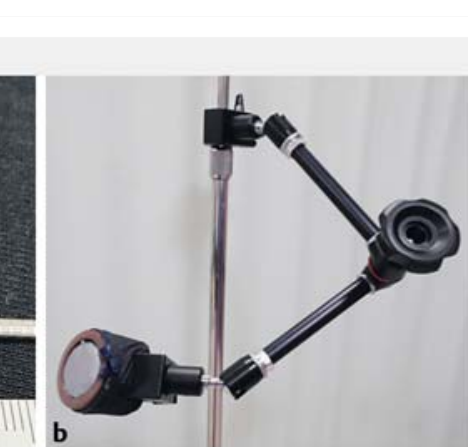

and the submucosal dissection was performed ( $>$ Fig.4). Thus, performance of MAG-ESD using a neodymium magnet and a stainless steel anchor was successful in this colonic case ( Video 1 ). The patient was discharged without adverse events. The procedure time was less than 30 minutes. The histopathological diagnosis was adenoma.

The feasibility of this technique should be assessed in a variety of anatomic locations.

Clinical trial registration number: UMIN000036360.

Endoscopy_UCTN_Code_TTT_1AQ_2AD

Competing interests

None

The authors

Ippei Matsuzaki ${ }^{1}$, Hiroki Yamauchi ${ }^{1}$, Naoya Goto $^{1}$, Yuji Iwata' ${ }^{1}$, Mafu Tsunemi², Makoto Kobayashi $^{3}$, Masashi Hattori ${ }^{1}$

1 Department of Gastroenterology, Yamashita Hospital, Ichinomiya, Japan

2 Department of Nursing, Yamashita Hospital, Ichinomiya, Japan

3 Department of Gastroenterology, Yokkaichi Municipal Hospital, Mie, Japan

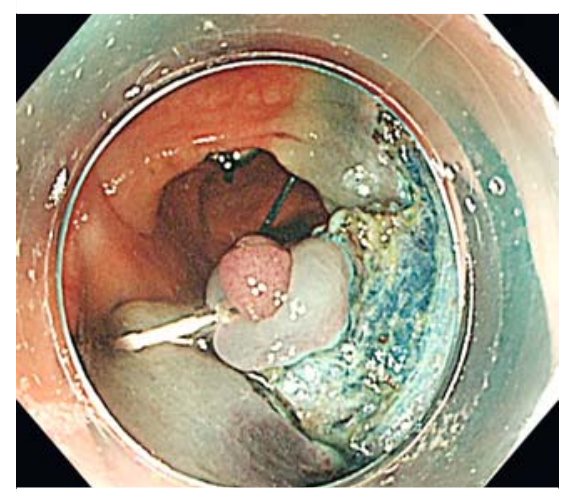

-Fig. 4 Direct visualization of the submucosal layer enabled by traction using the stainless steel anchor. steel anchor. a The stainless steel anchor attached with thread to an endoclip. b The external magnet attached to a flexible arm. 


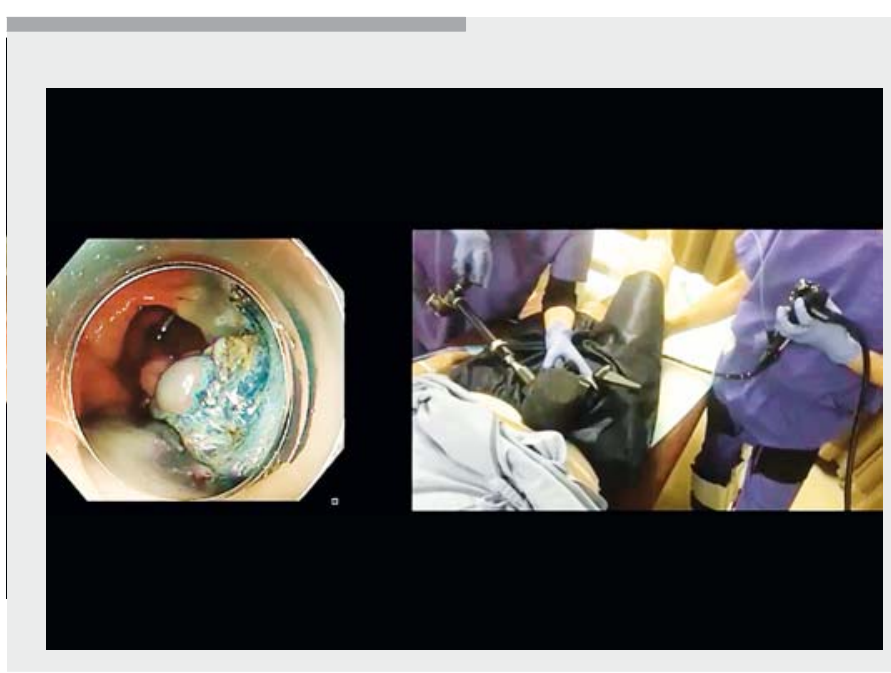

Video 1 Magnetic anchor-guided endoscopic submucosal dissection in a colonic case using a stainless steel anchor.

Masashi Hattori, MD, PhD

Department of Gastroenterology, Yamashita Hospital, 1-3-5 Nakamachi, Ichinomiya,

Aichi, 491-8531 Japan

Fax: +81-586-46-3118

m.hattori@yamashita.or.jp Hepatol 2007; 5: 678-683

\section{References}

[1] Fujishiro M, Yahagi N, Kakushima $\mathrm{N}$ et al. Outcomes of endoscopic submucosal dissection for colorectal epithelial neoplasms in 200 consecutive cases. Clin Gastroenterol

[2] Saito Y, Uraoka T, Yamaguchi Y et al. A prospective, multicenter study of 1111 colorectal endoscopic submucosal dissections (with video). Gastrointest Endosc 2010; 72 : $1217-1225$

[3] Matsuzaki I, Miyahara R, Hirooka Y et al. Simplified magnetic anchor-guided endoscopic submucosal dissection in dogs (with videos). Gastrointest Endosc 2014; 80: $712-716$
[4] Matsuzaki I, Hattori M, Hirose K et al. Magnetic anchor-guided endoscopic submucosal dissection for gastric lesions. Gastrointest Endosc 2018; 87: 1576-1580

[5] Matsuzaki I, Isobe S, Hirose K et al. Magnetic anchor-guided endoscopic submucosal dissection for colonic tumor. Gastrointest Endosc 2017; 85: 1111 - 1112

\section{Bibliography}

DOI https://doi.org/10.1055/a-0978-7739

Published online: 27.9.2019

Endoscopy 2020; 52: E80-E81

(c) Georg Thieme Verlag KG

Stuttgart · New York

ISSN 0013-726X

\section{ENDOSCOPY E-VIDEOS}

https://eref.thieme.de/e-videos

Endoscopy E-Videos is a free 留 回: on interesting cases and new techniques in gastroenterological endoscopy. All papers include a high quality video and all contributions are freely accessible online.

This section has its own submission website at

https://mc.manuscriptcentral.com/e-videos 